Article

\title{
Brassica juncea L. (Mustard) Extract Silver NanoParticles and Knocking off Oxidative Stress, ProInflammatory Cytokine and Reverse DNA Genotoxicity
}

\author{
Sohair Aly Hassan ${ }^{1, *}$, Ali Mohamed El Hagrassi ${ }^{2}$, Olfat Hammam ${ }^{3}$, \\ Abdelmohsen M. Soliman ${ }^{1}$ (D), Essam Ezzeldin ${ }^{4}$ and Wessam Magdi Aziz ${ }^{1}$ (D) \\ 1 Therapeutic Chemistry Department, Pharmaceutical Industries Division, National Research Centre, \\ 33 El Bohouth St., Dokki, Giza 12622, Egypt; solimanmohsen@yahoo.com (A.M.S.); \\ wessamagdi@yahoo.com (W.M.A.) \\ 2 Phytochemistry and Plant Systematics Department, Pharmaceutical Industries Division, National Research \\ Centre, 33 El Bohouth St., Dokki, Giza 12622, Egypt; alielhagrasi@gmail.com \\ 3 Pathology Department, Theodor Bilharz Research Institute, P.O. Box 30, El Warraq, Giza Governorate 12411, \\ Egypt; totoali1@hotmail.com \\ 4 Department of Pharmaceutical Chemistry, College of Pharmacy, King Saud University, P.O. Box 2457, \\ Riyadh 11451, Saudi Arabia; esali@ksu.edu.sa \\ * Correspondence: sohaireslamaya@hotmail.com
}

Received: 8 October 2020; Accepted: 4 December 2020; Published: 9 December 2020

\begin{abstract}
Detoxification is one of the main vital tasks performed by the liver. The purpose of this study was to investigate whether mustard in its normal or nanoparticles could confer a protective/therapeutic effect against TAA-induced acute liver failure in experimental animal models. Mustard ethanolic extract was analyzed by HPLC/MS. To induce liver failure, male rats were injected with $350 \mathrm{mg} / \mathrm{kg}$ bw TAA IP, then treated orally with a dose of $100 \mathrm{mg} / \mathrm{kg}$ for $15 \mathrm{~d}$ of mustard extract and its nanoform before and following induction. The levels of serum liver functions, total cholesterol (TCHo), total glyceride (TG), total bilirubin (TBIL), hepatic malonaldhyde (MDA) and nitric oxide (NO),glutathione (GSH), sodium oxide dismutase (SOD), as well as tumor necrosis factor (TNF- $\alpha$, ) and interleukin 6 (IL-6), were estimated. DNA genotoxicity and hepatic pathology, and immunohistologic (IHC) changes were assayed. The antioxidant content of Phenolic acids, flavonoids in mustard ethanolic extract substantially decreased the levels of ALT, AST, ALP and rehabilitated the histopathological alterations. In addition, nanoforms of mustard ethanol extract have notably increased the levels of GSH, SOD and significantly reduced the levels of MDA. The expression levels of TNF- $\alpha$ and IL-6 in serum and tissue were markedly downregulated. DNA genotoxicity was significantly reversed. Mustard introduced a protective and medicinal effect against TAA in both its forms.
\end{abstract}

Keywords: Thioacetamide (TAA); acute liver toxicity; Brassica juncea L. seeds extract; LC/MS; phenolic compounds; pro-inflammatory cytokine; DNA genotoxicity

\section{Introduction}

The liver is one of the most important organs responsible for the process of metabolism and selective uptake and clearance of drugs xenobiotic and environmental toxins, the matter which makes it very sensitive to drug toxicity [1]. Thioacetamide C2H5NS/TAA is an organosulfur compound known to induce acute or chronic liver disease (fibrosis and cirrhosis) in the experimental animal model very similar to that happen in humans. TAA toxicity results from a series of biotransformation into toxic metabolites that takes place in cytochrome P-450 enzymes in the liver [2]. 
TAA toxicity is triggered by its reactive metabolite sulfene or sulfone via the CYP450 system [3], which affects the most internal vital activities and causes oxidative stress and glutathione (GSH) depletion. Usually, in normal circumstances, these metabolites are detoxified by conjugating with antioxidative defense system (glutathione), but TAA toxic metabolites overwhelm the detoxification process and lead to a change in cell membrane permeability, disturb mitochondrial activity leading to lipid peroxidation, which contributes to the release of, cytokines, and prostaglandins [4,5] Thus, in initiating severe liver toxicity, the reactive oxygen species (ROS) may be the maestro by secreting a range of pro-inflammatory factors that could hurt DNA [6]. Considering the unappreciated side effects of chemically modified agents and the limited capacity of the modified pharmaceutical product to regulate major diseases, it is important to recognize new medicinal structures from other naturally occurring sources, including plant kingdom sources [7].

Brassica juncea L. seeds. Family Brassicaceae, is popularly known as Indian mustard, has both therapeutic and edible qualities. It has crucial contents of polyphenolic and phenolic compounds). Mustard preparations are well known for their mildly laxative, diuretic, and calming effect on the liver bile [8]. Mustard seeds since ancient times have been used by mankind for its culinary, as well as medicinal, properties. It has been systematically described and used in the classical Ayurvedic to purge the toxins out of the body [9]. The leaf extracts of $B$ juncea have been reported to exhibit antioxidant, antinociceptive, and antihyperglycemic activities both in vitro and in vivo [10]. The leaf extracts of $B$. juncea have also been reported to significantly prevent the development of insulin resistance in rats [11]. Joint pain, nausea, alleviation of cough and colds, reducing swelling, and cranial cleaning were aptly treated with its extracted oil. Mustard oil has also been used for wound healing and skin diseases [9]. Nevertheless, the mechanism responsible for the protective effect of $B$. juncea seed extract in the context of TAA-induced liver failure in rat models still remains unknown.

In this study, we hypothesized that the nanotransformation of various phenolic and other compounds in mustard extract using $\mathrm{AgNO}_{3}$ couldimprove its benefits for health.

Thus, the purpose of this study was to elucidate the therapeutic and restorative impacts of mustard and its silver nanoparticles against TAA induced acute liver failure in animal models through speculating the biochemical parameters, assess the oxidative stress, anti-inflammatory impact and genotoxicity as well as histology and immunohistopathological studies.

\section{Materials and Methods}

\subsection{Chemicals}

All Chemicals, Silver nitrate and thioacetamide were procured from Sigma-Aldrich (St. Louis, MO, USA). The different solvents and chemicals used in the present study were of high analytical grade and supplied by a local vendor.

\subsection{Authentication and Preparation of the Plant Extracts}

Mustard seeds(B. juncea)were purchased from a local retail store(Cairo, Egypt). Mustard seeds were identified by the taxonomy Dept (Faculty of Science., Cairo University), where a voucher specimen was deposited for future reference). The seeds were cleaned, grounded with a coffee grinder to a fine powder. The powder was stored in a clean bottle at room temperature in a dark place. The powdered seed samples $(100 \mathrm{~g})$ were weighed and extracted with $300 \mathrm{~mL}$ of $70 \%$ ethanol. Then left for $72 \mathrm{~h}$. for about 3 days using an end-to-end shaker at room temperature for $1 \mathrm{~h}$. The extracts were filtered through Whatman no 1 filter paper and then dried by rotary evaporation. The yield of $12.5 \mathrm{~g}$ was kept at $4^{\circ} \mathrm{C}$ until use [12].

\subsection{LC/MS Tentative Analysis for Ethanolic Extract of B. juncea L.}

Chemical and quantitative analysis of the main components of $100 \mathrm{~g}$ of mustard were analyzed. The sample $(100 \mu \mathrm{g} / \mathrm{mL})$ solution was prepared using high-performance liquid chromatography (HPLC) 
analytical grade solvent of $/ \mathrm{MeOH}$, filtered using a membrane disc filter $(0.2 \mu \mathrm{m})$, then subjected to LC-ESI-MS analysis. Samples injection volumes $(10 \mu \mathrm{L})$ were injected into the UPLC instrument equipped with reverse phase C-18 column (ACQUITY UPLC-BEH C18 $1.7 \mu \mathrm{m}$ particle size- $2.1 \times 50 \mathrm{~mm}$ Column). Sample mobile phase was prepared by filtering using $0.2 \mu \mathrm{m}$ filter membrane disc and degassed by sonication before injection. Mobile phase elution was made with the flow rate of $0.2 \mathrm{~mL} / \mathrm{min}$ using mobile gradient phase comprising two eluents: eluent $\mathrm{A}$ is $\mathrm{H}_{2} \mathrm{O}$ acidified with $0.1 \%$ formic acid, and eluent $\mathrm{B}$ is $\mathrm{MeOH}$ acidified with $0.1 \%$ formic acid. Elution was performed using the above gradient. The parameters for analysis were carried out using negative ion mode as follows: source temperature $150^{\circ} \mathrm{C}$, cone voltage $30 \mathrm{eV}$, capillary voltage $3 \mathrm{kV}$, desolvation temperature $440^{\circ} \mathrm{C}$, cone gas flow $50 \mathrm{~L} / \mathrm{h}$, and desolvation gas flow $900 \mathrm{~L} / \mathrm{h}$. Mass spectra scanning was detected in the ESI negative ion mode between $m / z$ 100-1000. The peaks and spectra were processed using the MassLynx 4.1 software and tentatively identified by comparing its retention time $\left(R_{t}\right)$ and mass spectrum with reported data [13-15].

\subsection{Synthesis of Mustard Silver Nanoparticles}

B. juncea/mustard seed extract was used to synthesize (mustard-AgNPs). According to Hassan et al. [16], silver nitrate $(0.017 \mathrm{~g})$ was added in $100 \mathrm{~mL}$ of double distilled water to prepare $1 \mathrm{mM}$ silver nitrate solution. Then, $1 \mathrm{~mL}$ of ethanolic mustard extract was added to $50 \mathrm{~mL}$ of silver nitrate $(1 \mathrm{mM})$ solution and incubated for $24 \mathrm{~h}$ in a dark chamber to minimize photo-activation of silver nitrate at room temperature under static conditions for nucleation of the silver nanoparticles. The reduction of elemental $\mathrm{Ag}$ to $\mathrm{AgO}$ was confirmed by the color change from colorless to brownish-yellow, indicating that ethanolic mustard extract was encapsulated into the silver nanoparticles in the form of pellets. The suspensions were subjected to centrifugation for the pellets to settle, which were then dried using a vacuum dryer.

\subsection{Characterization of Synthesized Silver Nanoparticles}

UV-vis spectral analysis was done by using Shimadzu visible spectrophotometer (UV-1800, Japan). The periodic scans of the optical absorbance between 300 and $700 \mathrm{~nm}$ with a double-beam UV-visible spectrophotometer (Carry 100 with tungsten halogen light sources) were performed at room temperature to investigate the reduction of silver ions by seed extract.

Field emission scanning electron microscopy (FESEM), the morphology, particle dispersion, and chemical composition of the prepared Nanostructures were investigated by (FESEM) (Quanta 450) equipped with EDS at accelerating voltage $30 \mathrm{kV}$ and further confirmed by transmission electron microscopy (TEM) for internal surface morphology using a JEOL JEM 1200 transmission electron microscope (JEOL Ltd., Peabody, MA, USA) [17].

\subsection{Animals}

A total of 64 Westar rats weighing 180-200 $\mathrm{g}$ were taken from the breeding laboratory of the National Research Center and kept in an animal care facility. Rats were held in reserve in polypropylene cages at room temperature with a $12 \mathrm{~h}$ light-dark cycle and relative humidity of $60 \% \pm 1 \%$. Animals were provided purified water ad libitum with standard laboratory rat chow. The study was approved by the animal ethics committee of the Institutional Review Board of National Research Center [No 20061]. The animal protocol was designed to lessen pain or distress to the animals. TAA (Sigma-Aldrich Chemical, ST. Louis, MO, USA) was dissolved in physiological saline, and the appropriately selected dose of $350 \mathrm{mg} / \mathrm{kg}$ bw was injected intraperitoneal (i.p.) in $1 \mathrm{~mL}$ volume [3]. 
Experimental protocol

The rats were divided into 8 groups consisting of 8 rats each as follows:

- Group (G 1): Normal healthy cont. (3\% Tween-80) and water, respectively

- Group (G 2): Intoxicated group was treated intraperitoneal (i.p.) with $350 \mathrm{mg} / \mathrm{kg}$ bw of freshly prepared TAA in a single shot [3], 5\% glucose solution was added to the drinking water to avoid dehydration $24 \mathrm{~h}$ post-injection.

- Groups (G3, G4): were given orally; the standard plant extract and its nano forms (NMs) in a dose of I $\mathrm{mL}[100 \mathrm{mg} / \mathrm{kg}]$ for two weeks as a benchmark/control group of plant extract [12].

- Prophylactic groups (G5, G6): administered a dosage of $1 \mathrm{~mL}$ of standard mustard extract and/or its nanoform for two weeks prior to i.p. TAA insulting $350 \mathrm{mg} / \mathrm{kg}$ bw in one shot, by then continued with the same dosage of $1 \mathrm{~mL}$ of both extracts for two weeks.

- Treatment groups (G7, G8): were given orally; the standard plant extract and its nanoforms in a dose of $1 \mathrm{~mL}$ as a treatment for two weeks after (i.p.) single injection with the same assigned dose of TAA. Twenty-four hours following the last drug administration, blood samples were withdrawn from the retro-orbital plexus of the rats under light ether anesthesia. Then, rats were sacrificed by cervical dislocation under the same anesthesia for the collection of liver samples. A weighed part of the liver of each animal was rapidly dissected out, washed and homogenized using phosphate-buffered saline (PBS, $50 \mathrm{mM}$ potassium phosphate, $\mathrm{pH} 7.5$ ) at $4^{\circ} \mathrm{C}$ to produce a $20 \%$ homogenate. Liver homogenates were kept at $-80^{\circ} \mathrm{C}$ until analysis. Another part of liver tissue was kept in $10 \%$ formalin-saline for histopathological and immunohistopathological examinations.

\subsection{Biochemical Analysis}

The liver function indices in terms of serum alanine aminotransferase (ALT), aspartate aminotransferase (AST) and alkaline phosphatase (ALP), total bilirubin (TBIL) and total lipid (TP) were estimated in the serum by colorimetric method using bio diagnostic kits (Biogamma, Rome, Italy, Stanbio, Barleben, Germany). Furthermore, total cholesterol (TC), triglyceride (TG) was estimated in the serum sample by enzymatic Colorimetric Method using bio diagnostic kits (Biogamma, Stanbio). The oxidative stress markers, lipid peroxidation (LPO), glutathione (GSH), superoxide dismutase (SOD) and nitric oxide (NO), were evaluated in the liver tissue homogenates according to Buege and Aust [18], Moron et al. [19], Nishikimiet et al. [20],Moshage et al. [21],respectively. Liver total protein contents were estimated following Bradford [22]. The DNA fragmentation index was estimated via the comet assay technique as described by Masoomi Karimi et al. [23]. The pro-inflammatory cytokines TNF- $\alpha$, IL-6 were assayed in the serum sample using commercially available ELISA kits (R\&D, Minneapolis, MN, USA).

\subsection{Histopathological Studies}

A division of the liver was preserved in $10 \%$ buffer formalin for at least $24 \mathrm{~h}$. and then embedded in paraffin according to the standard protocol. Sections were cut into $5 \mu \mathrm{m}$-thick portions, transferred onto glass slides, and stained with hematoxylin and eosin (HE), investigated microscopically for any histopathological and immunohistochemical changes as well [24]

Histopathological and Immunohistochemical Examinations

Five micrometer-thick sections of paraffinized liver stained with hematoxylin and eosin were examined histopathologically under Zeiss microscope (Carl Zeiss Microscopy GmbH 07,745 Jena, Germany) with $\times 200, \times 400$ magnification powers. For immunohistochemical examinations of IL6, TNF $\alpha$ were performed on liver sections cuts from the paraffin blocks with a commercially available anti-mouse IL6, TNF $\alpha$ antibodies (Santa Cruz Biotechnology, CA, USA) at the optimal working dilution of 1:100. Briefly, slides were sectioned at $4 \mu \mathrm{m}$ onto positively charged slides (Super frost plus, Menzel-Glaser, Germany), and the slides were stained on an automated platform (Dako Autostainer 
Link 48). Heat-induced antigen retrieval was used for $30 \mathrm{~min}$ at $97^{\circ} \mathrm{C}$ in the high-PH Envision ${ }^{\mathrm{TM}}$ FLEX Target Retrieval Solution, and the primary antibody was used at a dilution of 1 in 100 . The percent of positively stained brown cytoplasm (IL6, TNF $\alpha$ ) were examined in 10 microscopic fields (under Zeiss light microscopy at $\times 400)$.

\subsection{Statistical Analysis}

Statistical analysis of all data was expressed as mean \pm SD of 8 rats in each group by using one-way analysis of variance (ANOVA), the CoStat software computer program accompanied with least significance difference (LSD) between groups at a significant level at $p<0.05$. The percentage of improvement in both the prophylactic group and the treatment one was calculated according to the equation.

$$
\% \text { of improvement }=\frac{\text { Mean of TAA intoxicated group }- \text { Mean of treated group } \times 100}{\text { Mean of control }}
$$

\section{Results}

The current results revealed that the incubation of $50 \mathrm{~mL}$ of $1 \mathrm{mM} \mathrm{AgNO}$ with $1 \mathrm{~mL}$ of mustard extract for $24 \mathrm{~h}$ at "room temperature" led to the synthesis of AgNPs as indicated by the development of the brown color. The spectrophotometric analysis showed a maximum absorption picture of the developed brown color at $425 \mathrm{~nm}$ (Figure 1).

\subsection{The Visual Observation of Color Changes of Silver Nano Mustard (B. juncea) Extract}

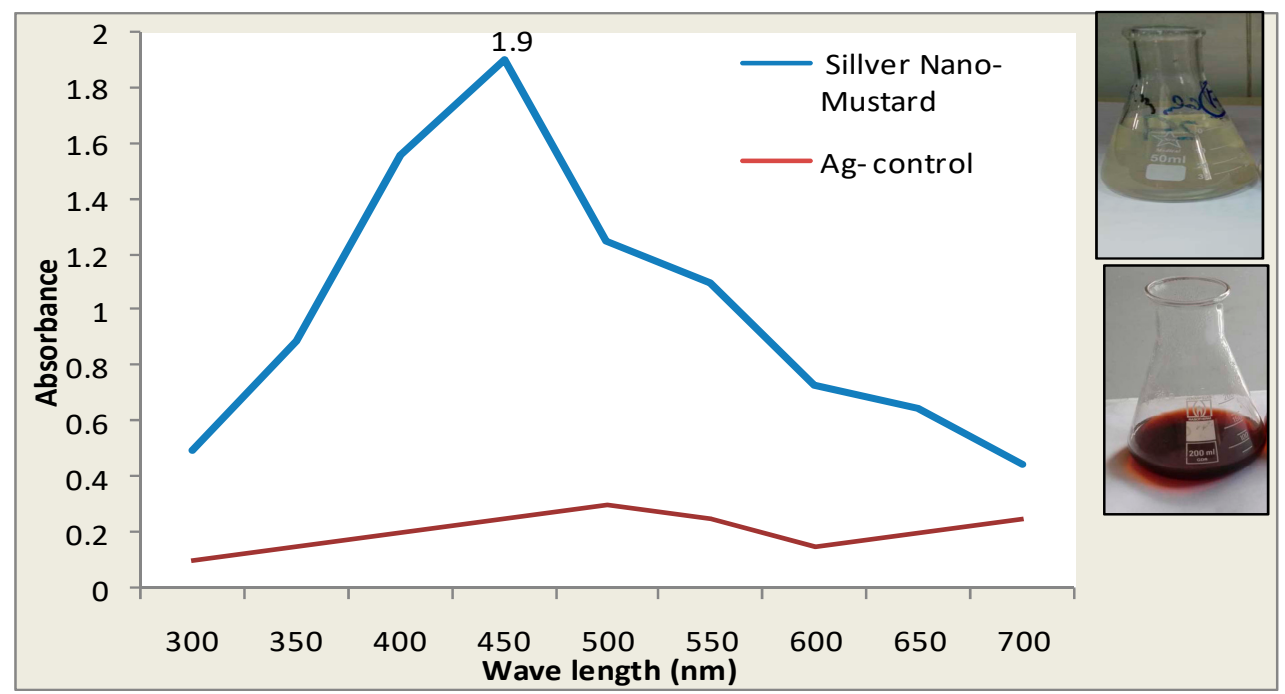

Figure 1. UV-visible spectrophotometric analysis of Ag mustard nanoparticles. Maximum absorption of Ag mustard nanoparticles at a wavelength of $425 \mathrm{~nm}$.

Moreover, the physical stability of the mustard-nano silver structures was evaluated in terms of $\xi$-potential. The surface charge of all the silver nanostructures of B. juncea seeds was negative, extending from [-10.6-13.3 mV]. The SEM \&TEM check demonstrated that AgNPs molecule size was in the nanostructure in the scope of 4.8-39.5 nm (Figure 2A,B). 


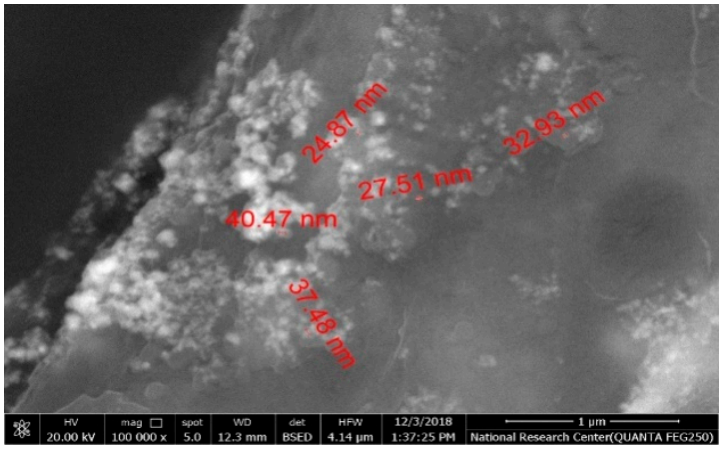

(A)

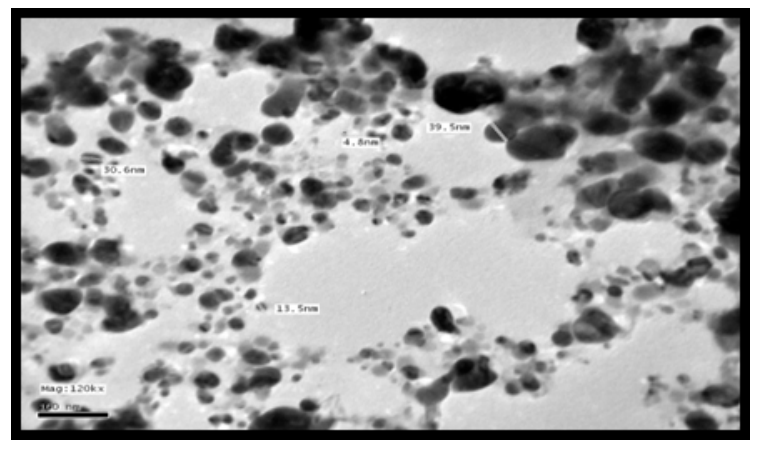

(B)

Figure 2. SEM (A) and TEM (B) micrographs of round state of Ag-nanoparticles of mustard with a size range from 4.8 to $39.5 \mathrm{~nm}$.

LC/MS results tentatively manifested twenty-eight phenolic compounds in the ethanolic extract of mustard. (Table 1, Figure 3). Fourteen phenolic acids and its glycosides were detected and determined as follow compounds $1,2,3,4$ and 5 were eluted at retention time $\left(R_{t}\right) 13.30,15.22,16.51$ and $18.11 \mathrm{~min}$., which produced a molecular ion peak $[\mathrm{M}-\mathrm{H}]^{-}$at $m / z, 179,163,223,193$ and 191 and identified as caffeic acid, $p$-coumaric acid, sinapic acid, ferulic acid and quinic acid, respectively.

Peaks 6 and 7 are identified as 3-caffeoylquinic acid and 3-feruloylquinic acid detected with $[\mathrm{M}-\mathrm{H}]^{-}$at $m / z 353$ and 367, which yielded fragment ions at $m / z(191,179,135)$ and $(191,193,149)$. Compounds 8, 9 and 10 were eluted at retention time $\left(R_{t}\right) 21.20,21.44$ and $22.31 \mathrm{~min}$. detected with [M $-\mathrm{H}]^{-}$at $m / z 355,341$ and 385, which referring to ferulic acid and caffeic acid after losing of hexose unit; thus, compound 8 was identified as ferulic acid hexoside, compound 9 was identified as caffeic acid hexoside, and compound 10 was identified as sinapic acid hexoside. Peaks 11, 12 and 13 were identified as $p$-coumaroyl malic acid, feruloyl malic acid and sinapoyl malic acid with $[\mathrm{M}-\mathrm{H}]^{-}$at $\mathrm{m} / \mathrm{z}$ 279, 309 and 339. Compound 14 was identified as rosmarinic acid at $[\mathrm{M}-\mathrm{H}]^{-}$at $\mathrm{m} / z 359$.

The two flavanol aglycone compounds peaks 15 and 16 were identified as kaempferol and quercetin with $[\mathrm{M}-\mathrm{H}]^{-}$at $\mathrm{m} / z 285$ and 301. In addition to twelve flavanol glycoside compounds were identified as kaempferol $O$-dihexoside (compound 17), which appeared with molecular ion peak $[\mathrm{M}-\mathrm{H}]^{-}$at $m / z 609$ with fragments at $m / z$ (477 and 285) corresponding to the kaempferol as aglycone after losing of two hexose units. In addition, peak 18 was identified as kaempferol-O-hexoside, which produced a molecular ion peak at $m / z 447$, corresponding to the kaempferol as aglycone after losing of hexose unit. 
Table 1. LC-MS analysis of ethanolic Brassica juncea L. (mustard) extract.

\begin{tabular}{|c|c|c|c|c|c|}
\hline $\begin{array}{c}\text { Peak } \\
\text { No }\end{array}$ & $\underset{\text { (min.) }}{\mathbf{R}_{\mathrm{t}}}$ & {$[\mathrm{M}]$} & $\begin{array}{c}{[\mathbf{M}-} \\
\mathbf{H}]^{-}\end{array}$ & $\begin{array}{c}\text { Fragments } \\
\qquad \mathrm{m} / \mathrm{z}\end{array}$ & Tentative Identification \\
\hline 1 & 13.3 & 180 & 179 & 135 & Caffeic acid \\
\hline 2 & 15.22 & 164 & 163 & 119 & $p$-Coumaric acid \\
\hline 3 & 16.51 & 224 & 223 & 179 & Sinapic acid \\
\hline 4 & 18.11 & 194 & 193 & 149 & Ferulic acid \\
\hline 5 & 19.21 & 192 & 191 & - & Quinic acid \\
\hline 6 & 19.52 & 354 & 353 & $191,179,135$ & 3-caffeoylqunic acid \\
\hline 7 & 20.1 & 368 & 367 & $191,193,149$ & 3-feruloylquinic acid \\
\hline 8 & 21.2 & 356 & 355 & 193,149 & Ferulic acid hexoside \\
\hline 9 & 21.44 & 342 & 341 & 163,135 & Caffeic acid hexoside \\
\hline 10 & 22.31 & 386 & 385 & 203,179 & Sinapic acid hexoside \\
\hline 11 & 23.23 & 280 & 279 & $163,133,119$ & $p$-Coumaroyl malic acid \\
\hline 12 & 23.51 & 310 & 309 & $193,149,133$ & Feruloyl malic acid \\
\hline 13 & 24.12 & 340 & 339 & $223,179,133$ & Sinapoy lmalic acid \\
\hline 14 & 25.05 & 360 & 359 & $\longrightarrow$ & Rosmarinic acid \\
\hline 15 & 25.55 & 287 & 286 & 一 & Kaempferol \\
\hline 16 & 25.41 & 302 & 301 & - & Quercetin \\
\hline 17 & 26.51 & 610 & 609 & 477,285 & Kaempferol-O-dihexoside \\
\hline 18 & 27.61 & 448 & 447 & 285 & Kaempferol-O-hexoside \\
\hline 19 & 28.52 & 772 & 771 & 609,285 & Kaempferol-O-cafeoyl dihexoside \\
\hline 20 & 29.50 & 756 & 755 & $609,447,285$ & Kaempferol-O- $p$-coumaroyl dihexoside \\
\hline 21 & 29.71 & 802 & 801 & $609,447,285$ & Kaempferol-O-hydroxyferuloyl dihexoside \\
\hline 22 & 29.81 & 788 & 787 & $625,463,301$ & Quercetin-O-trihexoside \\
\hline 23 & 30.10 & 626 & 625 & 463,301 & Quercetin-O-dihexoside \\
\hline 24 & 31.21 & 786 & 785 & $609,447,285$ & Kaempferol-O-feruloyl dihexoside \\
\hline 25 & 32.21 & 610 & 609 & 301 & Quercetin-3-O-rutinoside \\
\hline 26 & 33.32 & 464 & 463 & 301 & Quercetin-O-hexoside \\
\hline 27 & 33.50 & 918 & 917 & $755,609,447,285$ & Kaempferol-O-p-coumaroyl trihexoside \\
\hline 28 & 33.80 & 964 & 963 & $801,625,301$ & Quercetin-O-feruloyl trihexoside \\
\hline
\end{tabular}

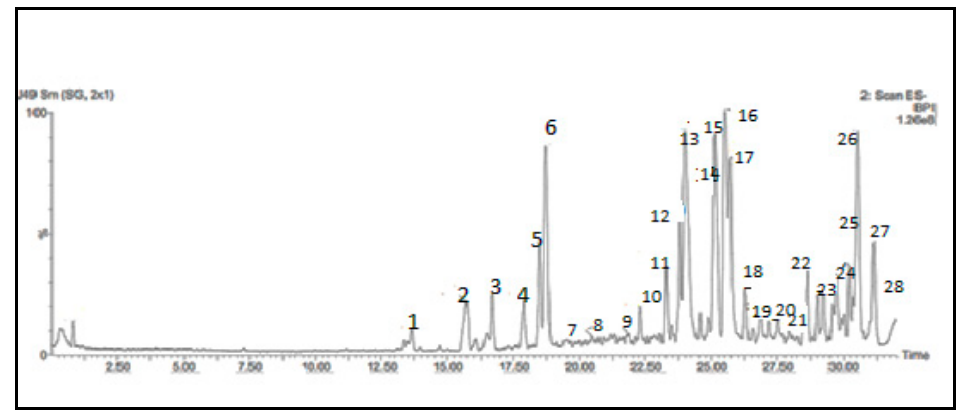

Figure 3. Total ion chromatogram of LC-MS of ethanolic extract of MS.

Compounds 19 and 20 are identified as kaempferol-O-cafeoyl dihexoside and kaempferol-O-p-coumaroyl dihexoside corresponding to a molecular ion peak $[\mathrm{M}-\mathrm{H}]^{-}$at $m / z 771$ and 755 with fragments $\mathrm{m} / \mathrm{z}$ $(609,285)$ and $(609,447$ and 285).

Peak 21 was eluted at retention time at 29.71 min with molecular ion peak $[\mathrm{M}-\mathrm{H}]^{-}$at $m / z 801$, which gave fragments at $m / z$ 609, 447 and 285 which corresponding to kaempferol-O-hydroxyferuloyl dihexoside.

Compound 22 and 23 were identified as quercetin- $O$-trihexoside and quercetin- $O$-dihexoside corresponding to molecular ion peak $[\mathrm{M}-\mathrm{H}]^{-}$at $m / z 787$ and 625 with fragments $(625,463,301)$ and $(463,301)$, which corresponding to quercetin as aglycone after losing three hexose units, while compound 23 lost two hexose units and quercetin as aglycone moiety.

Kaempferol-O-feruloyl dihexoside (compound 24) appears with molecular peak [M- $\mathrm{H}]^{-}$at $m / z 785$ with fragments $m / z(609,447$ and 285). Compound 25 and 26 were identified as quercetin-3-O-rutinoside 
and quercetin-O-hexoside, with molecular peak $[\mathrm{M}-\mathrm{H}]^{-}$at $\mathrm{m} / \mathrm{z} 609$ and 463 . Peak 27 at retention time 33.5 min showed the molecular ion peak $[\mathrm{M}-\mathrm{H}]^{-}$at $m / z 917$ with fragments 755, 609, 447, 285, which was identified as kaempferol-O-p-coumaroyl trihexoside.

Finally, Compound 28 at retention time 33.80 min was observed with molecular peak $[\mathrm{M}-\mathrm{H}]^{-}$at m/z 963 with fragments as 801, 625 and 301, corresponding to quercetin-O-feruloyl trihexoside [13-15].

\subsection{Effect of Brassica juncea L. (Mustard) Extract and Its Nanoforms on Liver Functions}

The examination of ALT, AST and ALP are given in (Table 2). Single injections of TAA (350 mg/kg bw) significantly elevated the serum activities of ALT, AST and ALP by 2.3, 2.7 and 1.9-fold respectively at $P<0.0001$ compared to the normal control group. Administration of ethanolic extraction of $B$. Juncea at doses of $100 \mathrm{mg} / \mathrm{kg}$ bw was a prophylactic and/or treatment substantially dwindled the elevation of transaminases with different percentages of improvement, which are represented in Table 2.

Table 2. Restorative and prophylactic impacts of Brassica juncea L. (mustard) extract in its normal and its nanostructure on liver function parameters.

\begin{tabular}{|c|c|c|c|}
\hline Groups Parameters & ALT $(\mathrm{U} / \mathrm{mL})$ Mean \pm SD & AST $(\mathrm{U} / \mathrm{mL})$ Mean \pm SD & $\operatorname{ALP}(\mathrm{U} / \mathrm{L})$ Mean $\pm \mathrm{SD}$ \\
\hline & Improvement $\%$ & Improvement $\%$ & Improvement $\%$ \\
\hline Control (-ve) & $53^{b} \pm 7.4$ & $56.2^{b} \pm 8.07$ & $115.4^{\mathrm{d}} \pm 14.70$ \\
\hline TAA (+ve) & $124^{a} \pm 10.20$ & $156.6^{a} \pm 9.64$ & $215.4^{a} \pm 9.36$ \\
\hline Control-Mustard (Ms) & $51.4^{\mathrm{b}} \pm 8.45$ & $61.2^{b} \pm 6.05$ & $138.2^{c} \pm 6.18$ \\
\hline $\begin{array}{l}\text { Control- Ag nano Mustard } \\
\text { (NMs) }\end{array}$ & $62.8^{b} \pm 7.89$ & $68.8^{b} \pm 8.28$ & $125.4^{\mathrm{cd}} \pm 13.65$ \\
\hline Prophylactic-Mustard (PMs) & $68^{b} \pm 8.60(105 \%)$ & $66.6^{b} \pm 6.35(163 \%)$ & $171^{b} \pm 12.74(38 \%)$ \\
\hline $\begin{array}{c}\text { Prophylactic } \\
\text { Ag-nano-Mustard (PNMs) }\end{array}$ & $62.2^{b} \pm 9.20(116 \%)$ & $62.8^{\mathrm{b}} \pm 8.05(168 \%)$ & $132.4^{\mathrm{cd}} \pm 7.04(72 \%)$ \\
\hline Treated-Mustard (TMs) & $58.2^{b} \pm 8.50(125 \%)$ & $54.6^{b} \pm 7.75(182 \%)$ & $141.2^{\mathrm{c}} \pm 5.26(64 \%)$ \\
\hline $\begin{array}{l}\text { Treated Ag nano-Mustard } \\
\text { (TNMs) }\end{array}$ & $55.4^{\mathrm{b}} \pm 11.09(130 \%)$ & $57.8^{\mathrm{b}} \pm 8.07(177 \%)$ & $121.40^{\mathrm{cd}} \pm 15.63(82 \%)$ \\
\hline
\end{tabular}

Data are mean \pm SD of 8 rats in each group. Statistical analysis was done using one-way analysis of variance (ANOVA) using the CoStat computer program accompanied by the least significant level (LSD) between groups at $p<0.05$. Unshared superscript letters are significant values between groups at $p<0.0001$.

\subsection{Effect of Brassica juncea L. (Mustard) Extract in Their Normal and Its Nanoforms on Lipid Profile Parameters}

Table 3 shows that experimental groups treated with TAA demonstrated a significant increase in the serum levels of total cholesterol (TC), triglycerides (TG), total lipids (TP), total bilirubin (TBIL) as compared with the healthy control group at $(p<0.05)$. Pretreatment with $100 \mathrm{mg} / \mathrm{kg}$ bw of B. juncea plant extract before and after intoxication with TAA and post-treatment with the same dose both resulted in a decrease of the above-mentioned parameters with mean levels differing from the normal and TAA groups at $(p<0.0001)$. However, the largest percentage of improvement change was achieved by nano plant extract rather than the remaining treatment classes. 
Table 3. Restorative and prophylactic impacts of Brassica juncea L. (mustard) extract in its normal and its nanostructure on lipid profile.

\begin{tabular}{ccccc}
\hline Groups Parameters & $\begin{array}{c}\text { Total Cholesterol } \\
(\mathbf{m g} / \mathrm{dL}) \text { Mean } \pm \text { SD }\end{array}$ & $\begin{array}{c}\text { Total Glycerides } \\
(\mathbf{m g} / \mathrm{dL}) \text { Mean } \pm \text { SD }\end{array}$ & $\begin{array}{c}\text { Total Lipids (g/dL) } \\
\text { Mean } \pm \text { SD }\end{array}$ & $\begin{array}{c}\text { Total Bilirubin } \\
(\mathbf{m g} / \mathrm{dL}) \text { Mean } \pm \text { SD }\end{array}$ \\
\hline & Improvement $\%$ & Improvement $\%$ & Improvement $\%$ & Improvement $\%$ \\
\hline Control (-ve) & $40.36^{\mathrm{d}} \pm 1.8$ & $100.6^{\mathrm{e}} \pm 12.02$ & $0.39^{\mathrm{d}} \pm 0.035$ & $1.15^{\mathrm{b}} \pm 0.095$ \\
\hline TAA (+ve) & $90.25^{\mathrm{a}} \pm 2.37$ & $283.2^{\mathrm{a}} \pm 18.99$ & $0.92^{\mathrm{a}} \pm 0.036$ & $2.34^{\mathrm{a}} \pm 0.125$ \\
\hline $\begin{array}{c}\text { Control-Mustard(Ms) } \\
\text { Control-Ag nano Mustard } \\
\text { (NMs) }\end{array}$ & $58.81^{\mathrm{b}} \pm 9.45$ & $135.8^{\mathrm{d}} \pm 12.40$ & $0.44^{\mathrm{d}} \pm 0.035$ & $1.22^{\mathrm{b}} \pm 0.09$ \\
\hline Prophylactic-Mustard (PMs) & $54.65^{\mathrm{cd}} \pm 3.51$ & $103.6^{\mathrm{e}} \pm 12.70$ & $0.42^{\mathrm{d}} \pm 0.025$ & $1.17^{\mathrm{b}} \pm 0.065$ \\
\hline $\begin{array}{c}\text { Prophylactic-Ag } \\
\text { nano-Mustard (PNMs) }\end{array}$ & $50.2^{\mathrm{c}} \pm 3.70(99 \%)$ & $196^{\mathrm{b}} \pm 23.60(87 \%)$ & $0.66^{\mathrm{b}} \pm 0.050(67 \%)$ & $1.25^{\mathrm{b}} \pm 0.11(95 \%)$ \\
\hline Treatment-Mustard (TMs) & $60.5^{\mathrm{b}} \pm 3.65(73 \%)$ & $193.8^{\mathrm{c}} \pm 16.60(116 \%)$ & $0.59^{\mathrm{c}} \pm 0.040(85 \%)$ & $1.36^{\mathrm{b}} \pm 0.095(85 \%)$ \\
\hline $\begin{array}{c}\text { Treatment-Ag nano-Mustard } \\
\text { (TNMs) }\end{array}$ & $57.52^{\mathrm{b}} \pm 4.085(80 \%)$ & $173.6^{\mathrm{bc}} \pm 16(109 \%)$ & $0.66^{\mathrm{b}} \pm 0.070(67 \%)$ & $1.30^{\mathrm{b}} \pm 0.11(90 \%)$ \\
\hline
\end{tabular}

Data are mean \pm SD of 8 rats in each group. Statistical analysis was done using one-way analysis of variance (ANOVA) using the CoStat computer program accompanied by the least significant level (LSD) between groups at $p<0.05$. Unshared superscript letters with significant values between groups at $p<0.0001$.

\subsection{Effect of Brassica juncea L. (Mustard) Extract in Their Normal and Its Nanoforms on Oxidative Stress} Markers and Inflammatory Cytokines

A substantial decrease in the superoxide dismutase and glutathione levels in the challenged group following TAA injury $\mathrm{p}(p<0.0001)$. However, pre- and post-treatment with $B$. juncea extract could improve the deterioration in the antioxidant parameters compared to the control group. Groups treated with mustard extract and its nano form exhibited the best improvement percentage rather than the pretreatment groups. In contrast with oxidative parameters, which showed an increase in each lipid peroxidation and nitric oxide levels in the challenged TAA intoxicated group at $p<0.0001$ (Table 4). The treatment with Mustard extract (B. juncea) and its nanoforms showed a prominent reduction in oxidative parameters either as a prophylactic or as a treatment with different percentages of improvement (Table 4). The TAA-intoxication resulted in a remarkable elevation at $(p<0.05)$ in the measured inflammatory markers IL6 and TNF $\alpha$ by a 2.5-fold increase compared to the control group (Table 4). While B. Juncea extracts substantially reversed IL6 and TNF $\alpha$ levels in both preand post-treatment classes. In most antioxidant parameters as well as in inflammatory markers, the treatment with nanoform (TNMs) of B. juncea obtained the most amelioration outcomes. 
Table 4. Impacts of Brassica juncea L. (mustard) and its nanostructure on ROS and inflammatory cytokines.

\begin{tabular}{|c|c|c|c|c|c|c|}
\hline Groups Parameters & $\begin{array}{c}\text { SOD } \\
\text { (Umol/mg } \\
\text { Protein) } \\
\text { Mean } \pm \text { SD }\end{array}$ & $\begin{array}{c}\text { Glutathione } \\
(\mu \mathrm{g} / \mathrm{mg} \\
\text { Protein }) \\
\text { Mean } \pm \text { SD }\end{array}$ & $\begin{array}{c}\text { Lipid } \\
\text { Peroxidation } \\
\text { (Umol/mg } \\
\text { Protein) } \\
\text { Mean } \pm \text { SD }\end{array}$ & $\begin{array}{c}\text { Nitric oxide } \\
\text { (mmol/g } \\
\text { Tissue) } \\
\text { Mean } \pm \text { SD }\end{array}$ & $\begin{array}{l}\text { IL6 }(\mathrm{Pg} / \mathrm{mL}) \\
\text { Mean } \pm \mathrm{SD}\end{array}$ & $\begin{array}{c}\text { TNF- } \alpha \\
(\mathrm{Pg} / \mathrm{mL}) \\
\text { Mean } \pm \text { SD }\end{array}$ \\
\hline & Improvement $\%$ & Improvement $\%$ & Improvement $\%$ & Improvement $\%$ & Improvement $\%$ & Improvement $\%$ \\
\hline Control (-ve) & $125.21^{\mathrm{a}} \pm 8.60$ & $25.90^{\mathrm{a}} \pm 3.1$ & $3.03^{c} \pm 0.17$ & $11.28^{\mathrm{d}} \pm 1.70$ & $98.87^{\mathrm{f}} \pm 2.35$ & $62.38^{\mathrm{f}} \pm 1.71$ \\
\hline TAA (+ve) & $53.42^{\mathrm{d}} \pm 7.25$ & $10.10^{c} \pm 2.05$ & $7.5^{\mathrm{a}} \pm 0.47$ & $34.96^{\mathrm{a}} \pm 2.25$ & $236.77^{\mathrm{a}} \pm 9.95$ & $159.9^{a} \pm 2.14$ \\
\hline Control-Mustard (Ms) & $98.45^{b c} \pm 4.03$ & $23.17^{a} \pm 2.7$ & $4.11^{b} \pm 0.51$ & $18.36^{b} \pm 1.9$ & $125.18^{d} \pm 5.33$ & $75.91^{\mathrm{e}} \pm 5.46$ \\
\hline $\begin{array}{c}\text { Control- Ag nano Mustard } \\
\text { (NMs) }\end{array}$ & $92.08^{c} \pm 8.60$ & $24.98^{\mathrm{a}} \pm 1.8$ & $4.14^{b} \pm 0.25$ & $13.78^{\mathrm{cd}} \pm 2.24$ & $108.83^{e} \pm 5.18$ & $73.48^{\mathrm{e}} \pm 4.61$ \\
\hline $\begin{array}{c}\text { Prophylactic-Mustard } \\
\text { (PMs) }\end{array}$ & $\begin{array}{c}90.63^{c} \pm 9.64 \\
(29 \%)\end{array}$ & $\begin{array}{c}16.72^{b} \pm 1.65 \\
(26 \%)\end{array}$ & $\begin{array}{c}4.55^{\mathrm{b}} \pm 0.25 \\
(97 \%)\end{array}$ & $\begin{array}{l}18.90^{\mathrm{b}} \pm 2.50 \\
(142 \%)\end{array}$ & $\begin{array}{c}155.54^{\mathrm{b}} \pm 4.52 \\
(82 \%)\end{array}$ & $\begin{array}{c}139.86^{\mathrm{b}} \pm 5.15 \\
(32 \%)\end{array}$ \\
\hline $\begin{array}{c}\text { Prophylactic Ag } \\
\text { nano-Mustard (PNMs) }\end{array}$ & $\begin{array}{c}94.08^{c} \pm 7.35 \\
(32 \%)\end{array}$ & $\begin{array}{c}24.68^{\mathrm{a}} \pm 2.9 \\
(56 \%)\end{array}$ & $\begin{array}{c}3.89^{b} \pm 0.30 \\
(119 \%)\end{array}$ & $\begin{array}{c}15.97^{\mathrm{bc}} \pm 1.70 \\
(168 \%)\end{array}$ & $\begin{array}{l}141.33^{c} \pm 5.04 \\
(97 \%)\end{array}$ & $\begin{array}{l}127.61^{\mathrm{c}} \pm 5.14 \\
(51 \%)\end{array}$ \\
\hline Treatment-Mustard (TMs) & $\begin{array}{c}105.7^{\mathrm{bc}} \pm 9.85 \\
(42 \%)\end{array}$ & $\begin{array}{c}26.28^{a} \pm 2.85 \\
(62 \%)\end{array}$ & $\begin{array}{c}3.90^{\mathrm{b}} \pm 0.49 \\
(118 \%)\end{array}$ & $\begin{array}{l}18.35^{\mathrm{b}} \pm 2.70 \\
(147 \%)\end{array}$ & $\begin{array}{c}148.05^{\mathrm{c}} \pm 4.52 \\
(90 \%)\end{array}$ & $\begin{array}{c}135.65^{\mathrm{b}} \pm 3.85 \\
(39 \%)\end{array}$ \\
\hline $\begin{array}{c}\text { Treatment } \\
\text { Ag nano-Mustard (TNMs) }\end{array}$ & $\begin{array}{c}111.09^{b} \\
\pm 10.85(46 \%)\end{array}$ & $\begin{array}{c}25.61^{a} \pm 3.9 \\
(60 \%)\end{array}$ & $\begin{array}{c}4.12^{b} \pm 0.52 \\
(112 \%)\end{array}$ & $\begin{array}{c}16.43^{\mathrm{bc}} \pm 1.44 \\
(164 \%)\end{array}$ & $\begin{array}{c}120.38^{\mathrm{d}} \pm 6.54 \\
(118 \%)\end{array}$ & $\begin{array}{c}122.15^{\mathrm{d}} \pm 3.07 \\
(60 \%)\end{array}$ \\
\hline
\end{tabular}

Data are represented as mean \pm SD of 8 rats in each group. One-way analysis of variance (ANOVA) was employed using the CoStat computer program accompanied by the least significant level (LSD) between groups at $p<0.05$.

Unshared superscript letters are significant values between groups at $p<0.0001$.

\subsection{Effects of Brassica juncea L. (mustard) Extract and Its Nanoparticles on DNA Degradation}

Fragmentation of DNA was assessed using the comet assay. Compared to the normal control group, TAA has substantially caused DNA damage. This DNA damage was demonstrated significantly in terms of an increase in the comet parameters presented as tail length with different three classes (Figure 4A,B), tail and tail moment DNA (percentage); the primary predictive parameter for DNA damage (Table 5). In the hepatotoxic community, there was a large broom-like tail and a small comet eye (Figure 4A), a typical component of toxic DNA damage and apoptosis. The length of the tail increases as DNA damage increases, as seen in (Figure 4A,B). In the meantime, administration of Mustard (B. juncea) both in its natural or in its nano pretreatment has counterbalanced the TAA effect as demonstrated by a considerable reduction in the length of the tail; this changed into extra glaring in the mustard nano form (Table 5).

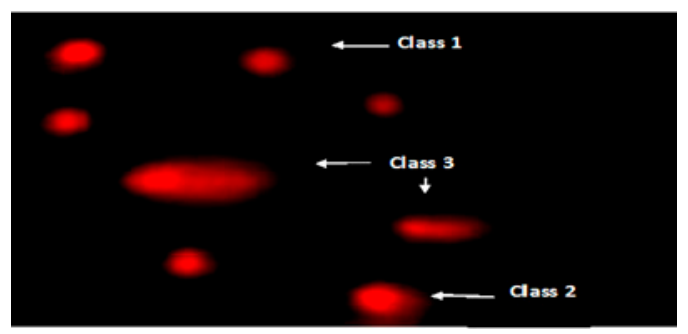

(a)

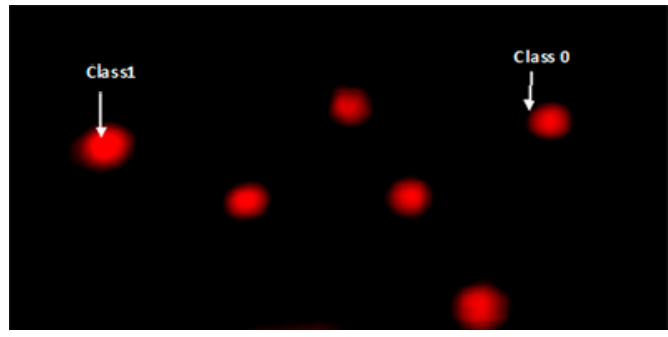

(b)

Figure 4. Comet assay in liver tissues shows visual DNA damage score: (a) classes 1, 2 and 3, (b) class 0 and 1. 
Table 5. Effects of Brassica juncea L. (mustard) and its nanoform on DNA degradation.

\begin{tabular}{|c|c|c|c|c|c|c|c|}
\hline \multirow[b]{2}{*}{ Treatment } & \multirow{2}{*}{\multicolumn{2}{|c|}{$\begin{array}{c}\text { No. of Cells } \\
\text { Analyzed Total Comets }\end{array}$}} & \multicolumn{4}{|c|}{ Class ${ }^{¥}$ of comet } & \multirow{2}{*}{$\begin{array}{l}\text { DNA Damaged } \\
\text { Cells (Mean } \pm \text { SD) }\end{array}$} \\
\hline & & & 0 & 1 & 2 & 3 & \\
\hline Control negative & 500 & 34 & 466 & 23 & 11 & 0 & $6.83 \pm 0.11^{d}$ \\
\hline TAA Control positive & 500 & 124 & 376 & 32 & 44 & 48 & $24.81 \pm 0.82^{a}$ \\
\hline Ms & 500 & 83 & 417 & 35 & 26 & 22 & $16.62 \pm 0.46^{b}$ \\
\hline AgNMs & 500 & 52 & 448 & 19 & 18 & 15 & $10.43 \pm 0.41^{c}$ \\
\hline $\begin{array}{c}\text { Prophylactic-mustard } \\
\text { PMs }\end{array}$ & 500 & 79 & 421 & 33 & 25 & 21 & $15.82 \pm 0.61^{b}$ \\
\hline $\begin{array}{c}\text { Prophylactic Ag } \\
\text { nano-mustard } \\
\text { PNMs }\end{array}$ & 500 & 59 & 441 & 21 & 23 & 15 & $11.80 \pm 0.44^{\mathrm{c}}$ \\
\hline Treatment TMs & 500 & 67 & 433 & 27 & 23 & 17 & $13.44 \pm 0.36^{b c}$ \\
\hline Treatment T AgNMs & 500 & 51 & 449 & 17 & 19 & 15 & $10.20 \pm 0.28^{c}$ \\
\hline
\end{tabular}

\subsection{Hematoxylin and Eosin Pathological Examination}

Liver sections of normal rats showed normal cellular architectures, normal morphology, hepatocyte and central vein (Figure 5A). The TAA-intoxicated group displayed partial distortion of hepatic lobular architecture, with moderate hydropic degeneration of hepatocytes and binucleated hepatocytes accompanied by vein congestion with thick fibrous tissue in the portal tract (Figure 5B). Mustard (B. juncea) treatment $(100 \mathrm{mg} / \mathrm{kg}$ ) pre-post either in normal or nanoforms has shown observable healing effect presented, as shown in (Figure $5 \mathrm{C}-\mathrm{H}$ ). 

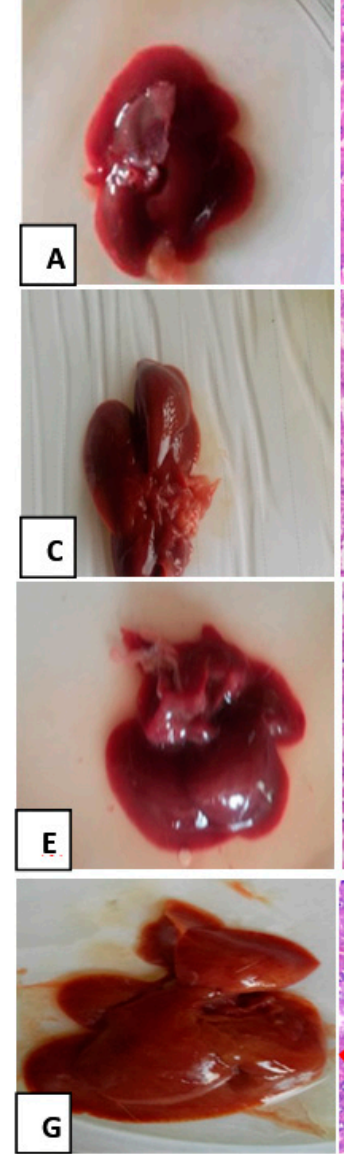
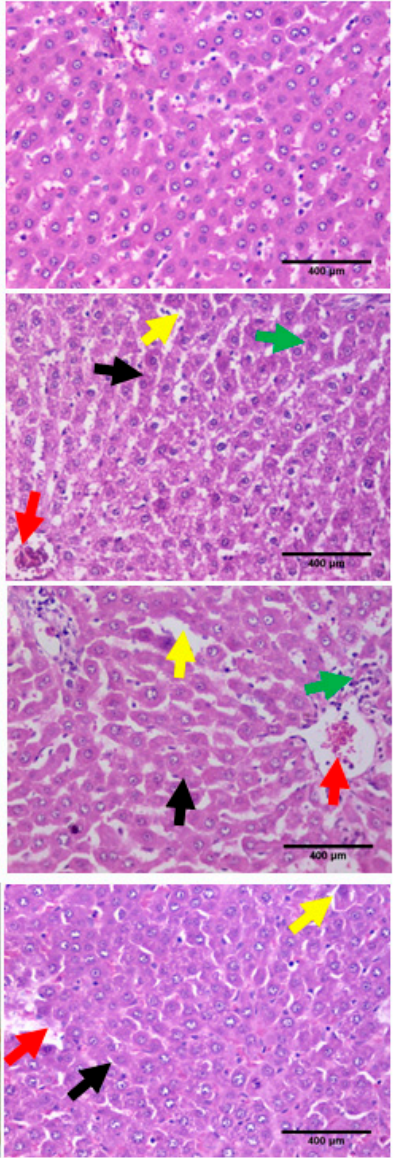

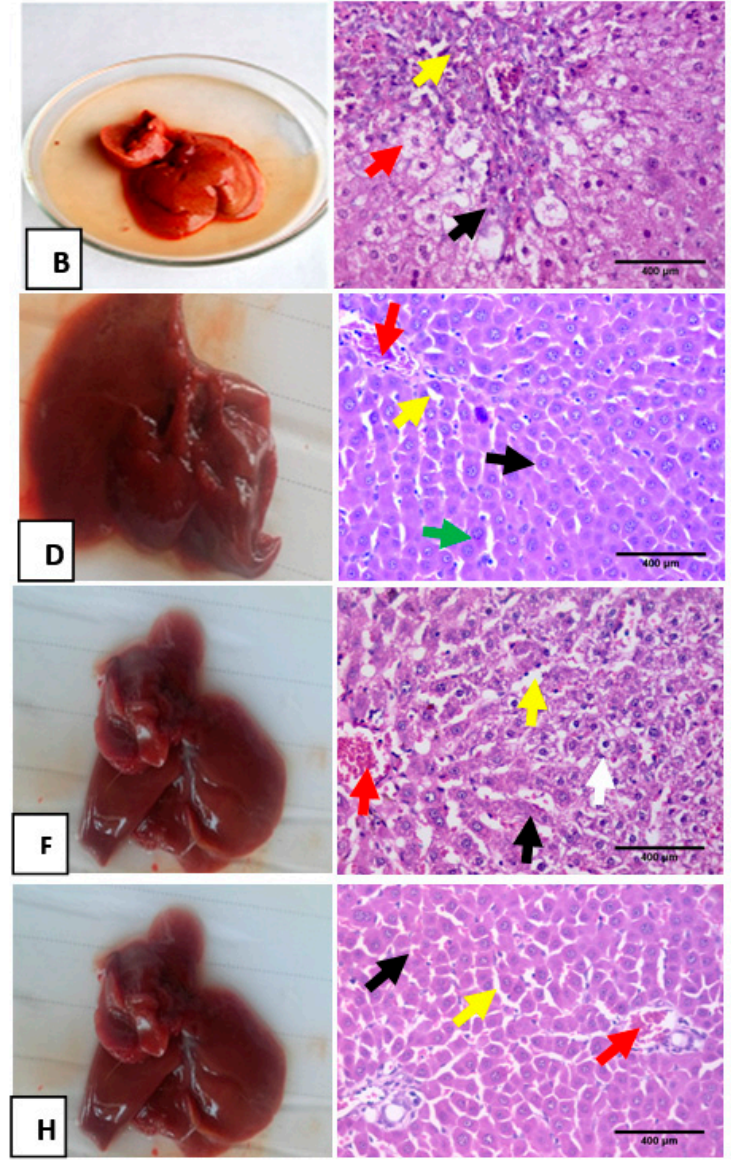

Figure 5. Photomicrograph of sections of hematoxylin and eosin ( $\mathrm{H}$ and $\mathrm{E}, \mathrm{x} 400)$ for liver tissues of different treated groups. (A) represents the sections from the normal control group with typical structure and morphology of the liver tissue; (B) TTA-intoxicated group showed severe abnormalities, partial distortion of lobular hepatic architecture (black arrow), with moderate hydropic degeneration of hepatocyte (red arrow) and thick fibrous tissue in portal tract (blue arrow); (C,D) liver sections treated with MS and nano MS showed hepatic tissue with almost normal intact hepatic lobular architecture and structure, hepatocytes arranged in thin plates (black arrow) and sinusoids (yellow arrow), central vein (red arrow), binucleated nuclei (green arrow); (E,F) liver sections treated orally with PMS nano PMS as a prophylactic group. They demonstrated tangible improvement as hepatic tissue was almost in normal intact hepatic lobular architecture and structure; hepatocytes arranged in thin plates (black arrow) with mild interlobular inflammatory infiltration (green arrow) and sinusoids (yellow arrow), congested central vein (red arrow), hepatocytes with moderate hydropic degeneration (white arrow); $(\mathbf{G}, \mathbf{H})$ liver sections treated with MS and MS nano groups showed improvement in hepatic tissues as it appeared in intact lobular hepatic architecture, hepatocyte with thin plates (black arrow), congested central vein (red arrow) and congested sinusoids (yellow arrow) $((\mathbf{H}, \mathbf{E}), \times 400)$.

\subsection{Impact of Mustard Extract and Its Nanoform on the Inflammatory Markers through Immunohistochemistry}

The anti-inflammatory effect of Mustard extract and its nano form was further evaluated via follow-up of the expression of IL-6 (Figure 6) and TNF- $\alpha$ (Figure 7) in hepatic tissues immunohistochemically. TAA intoxication $350 \mathrm{mg} / \mathrm{kg}$ bw resulted in a substantial elevation in TNF- $\alpha$ and IL-6 expression that were located mostly in the cytoplasm of hepatocytes in portal tract and fibrous septa compared to normal control group A, B. However, treatment with Mustard extract and its nanoforms either pre or after TAA intoxication improved and downregulated the expression of both TNF- $\alpha$ and IL6 Figures 6 and 7 from $(\mathrm{C}-\mathrm{H})$, respectively, with the notion indicated that nano mustard extract has more potential to inhibit the inflammatory response induced by TAA intoxication. 


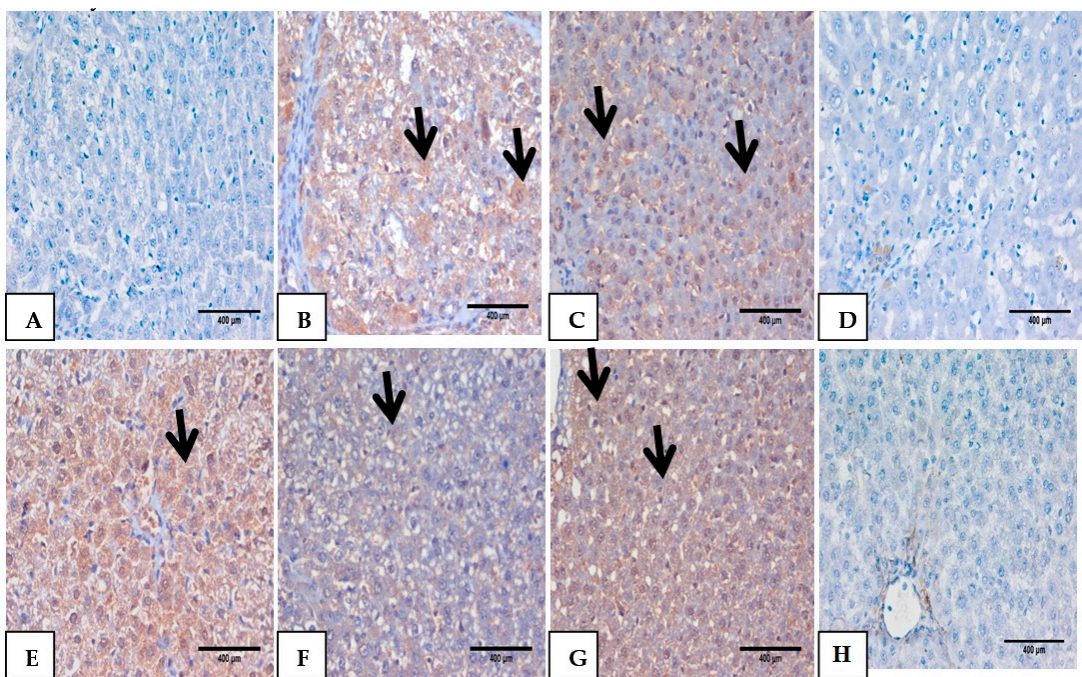

Figure 6. (A) Liver section stained with immunohistochemistry for IL6, (B) represents TAA +Ve intoxicated control group as it showed a dense expression of IL6 as a brownish cytoplasmic stain of hepatocytes in about $60 \%$ (black arrow), (C,D) liver sections pretreated with Ms and NMs showed a very light mild density of IL6 as brownish cytoplasmic stain $20 \%$,while NMs group sections showed a pronounced effect with negative expression of IL6 (black arrow), (E,F) liver sections from prophylactic (Ms and NMs) showed moderate improvement in brownish cytoplasmic stain IL6 expression 10-50\% (black arrow), $(\mathbf{G}, \mathbf{H})$ Liver sections treated with Ms and NMs show a marked improvement with a very light expression of IL6 10-50\% as a brownish cytoplasmic stain (black arrow) (DAB,IHC, $\times 400$ ).

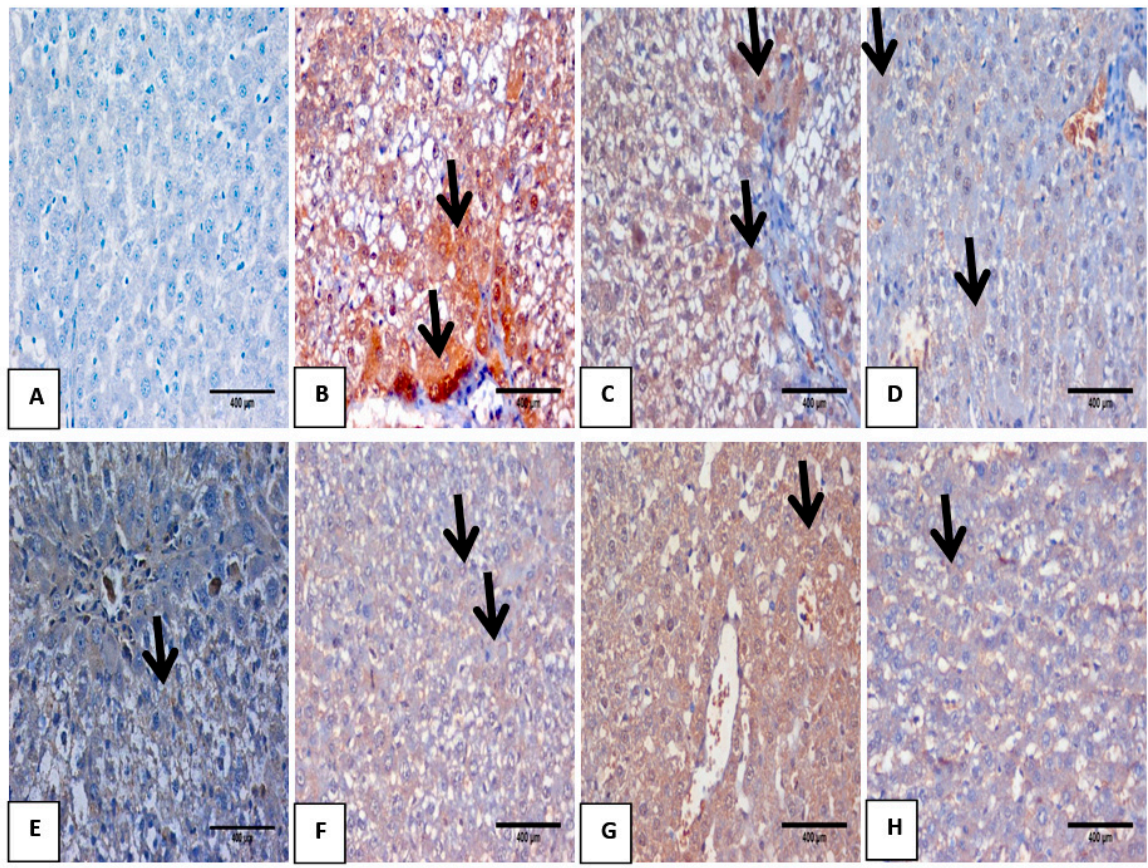

Figure 7. Liver section stained with immunohistochemistry for TNF- $\alpha$.from(A) normal control group showed negative expression of TNF- $\alpha$; (B) TAA intoxicated liver (positive control) showed marked expression of TNF- $\alpha$ as a brownish cytoplasmic stain of hepatocytes in about $\pm 70 \%$ (black arrow); (C,D) oral treatment with Ms and NM. As + ve control for mustard showed very mild expression of TNF- $\alpha$ as a brownish cytoplasmic stain of hepatocytes in about 10-20\% (black arrow); (E,F) liver section from pretreated groups of Ms and NMs demonstrated moderate expression of TNF- $\alpha$ as a brownish cytoplasmic stain of hepatocytes in about $\pm 20-30 \%$ (black arrow); $(\mathbf{G}, \mathbf{H})$ liver sections treated with Ms and NMs showed marked improvement of TNF- $\alpha$ expression as a brownish stain of hepatocytes in about $25-50 \%$ (black arrow) (DAB, IHC, $\times 400)$. 


\section{Discussion}

In the current study, green chemistry was employed to synthesize AgNPs using mustard seed extract (MSE). The change in the color of $\mathrm{AgNO}_{3}$ after $24 \mathrm{~h}$ incubation with (MSE) in the dark pointed to the ability of the extract of (MSE) to reduce $\mathrm{AgNO}_{3}$ to AgNPs. This result has been observed previously and indicated that the change in color might be appeared due to the surface plasmon resonance of the deposited AgNPs [25,26]. Formation of AgNPs was confirmed by the SEM and TEM as they ensured that the synthesized nanoparticles were within the nanoscale size $4.8-40 \mathrm{~nm}$. Mustard is an ancient plant known since Biblical times; subsequent scientific and pharmacological studies verified its antimicrobial, analgesic, anti-inflammatory, antipyretic, antidiabetic and hepatoprotective qualities [2,27]. Perhaps and to the best of our knowledge, no more published data about the impact of mustard in acute liver failure.

The present results revealed through the LC/MS analysis that mustard (B. juncea L.) seeds extract (MSE) is rich in phenolic acids and flavonoid compounds, kaempferols glycosides, fatty acids. Many studies indicated that phenolic and flavonoids compounds are directly contributed to the antioxidant activities [28]. These antioxidant properties of the plant phenolic compounds are primarily due to the redox properties of these compounds, which enable them to donate hydrogen, act as singlet oxygen quenchers and reducing agents, as mentioned previously [29].

Serum liver enzymes are biomarkers to monitor and display the injure and aids in the clinical diagnosis of liver toxicity conditions [30]. When there is an injury to the liver due to any cause, then these enzymes are spilled into the blood move. This was in complete agreement with our results, represented by a pronounced increase in the liver enzymes AST, ALT, and ALP in the serum as a response to TAA injection. A leakage was coupled with a loss of liver architecture, hydropic degeneration, central vein obstruction and hepatic lymphocytes infiltration (Table 1, Figure 5). As thioacetamide is a potent centrilobular hepatotoxicant, its effects have been extended to increase cholesterol, glyceride, total lipid, total bilirubin levels indicating oxidative damage of the liver (Table 3). However, a substantive improvement and reduction in these parameters were observed after remedy with $B$. juncea in its both forms either as a prophylactic or as a treatment; however, the nanoforms have shown a greater significant effect on the elevated serum liver enzymes and the rehabilitation of the liver architecture as well. These outcomes go in line with Yang et al. [31] and seem to be consistent with what recently announced by Khaled [32], Melrose [27] and Le et al. [33] as they archived the amazing cell reinforcement and hepatoprotective properties of mustard against poisonousness instigated free radicals harm in the liver and furthermore with Walia et al. [11] as he detailed ethanolic leaf concentrate of B. juncea could be a superior medication of decision as a hepatoprotective plant source. The free radicals scavenging effects of mustard extracts are most in all likelihood attributed to its better polyphenols and flavones contents.

It is worth noting that the antioxidant impact of polyphenols is mainly due to their redox properties, which allow them to behave as reducing agents, hydrogen donors, singlet oxygen quenchers, metal chelators [34,35]. Moreover, our findings showed a marked decrease with a sensible percentage of improvements in the levels of cholesterol, total glycerides, total lipids and total bilirubin when treated with mustard extract in its normal and in its nanoform either pre-or post-TAA administration. Result consequences can be interpreted on the basis of the phytocomponents structure of mustard seeds extract to have the potential to act in a synergistic way to lessen hyperlipidemia and hypercholesterolemia and go with full coincidence with Lee et al. [36] when they used B. juncea L. leaf extract on fat deposition and lipid profiles. The current observations suggest $B$. juncea L. seeds be clinically functional for treating dyslipidemia, although the mechanisms underlying still needed to be investigated.

In another hand bile, acid synthesis plays a major role in hepatic regulation of cholesterol homeostasis as well as in the catabolism of cholesterol bilirubin is considered a physiologically important antioxidant [37], with beneficial effects at mildly elevated concentrations, and can neutralize ROS and prevent oxidative damage [38-40]. These results may also provide an explanation for 
the increment of total bilirubin as a justification mechanism of the body against TAA free radicals. Interestingly mustard extract in its two forms, either pre- or post-treatment dose, showed a significant improvement in bilirubin level. That improvement was pronounced with the nano mustard treatment formula to be in concurrence with Rawat et al. [41].

As unquestionably demonstrated, oxidative stress and inflammation are the two essential players driving forces behind various diseases. This was confirmed by the significant decrease in GSH and SOD levels along with the elevation in MDA, serum NO together with the marked disturbances in TNF- $\alpha$ and IL6 levels (Table 4). These outcomes may confirm the hepatotoxic TAA and its capability to cause hepatic damage and act as an initiator for a series of serious inflammatory changes via ROS generation and antioxidant protection mechanism regulation [42,43].

It is well established that plant extracts with antioxidant potential can protect against the oxidative damage caused by TAA hepatotoxicity [2]. The present study confirmed this observation and demonstrated that mustard extract and its nanoform substantially increased the levels of GSH and SOD, whether pre- or post-TAA injection. Our findings may be in full settlement with Keshari et al. [44] as they reported that stimulation of the Nrf2/ARE pathway is essential for antioxidant defense enzyme induction and intracellular GSH modulation in response to stress. Consequently, mustard can play an antioxidant role in acute liver damage. Interestingly, mustard extract and its nano remodulated the level of lipid peroxide, restoring it back to near normal. It additionally decreased the overproduction of NO, which is commonly linked to the lack of cytochrome P450 content and injury in rat hepatocytes [45].

Moreover, a marked increase in serum levels of TNF- $\alpha$ and IL6 pro-inflammatory markers had been recorded in the challenged TAA group in both serum and tissue in comparison to the control results (Table 4 and Figure 6). It can clearly be seen the expression of TNF- $\alpha$ andIL6 is about $70 \%$. These findings may ensure that the entire inflammatory cascade, including the activation of transcription factors, is activated when the redox status is attached [46-48]. However, these parameters were remodulated and downregulated by mustard extract treatment in both normal and its nano form either pre-or post TAA intoxication. These good responses may be supportive of Le et al. [33] as they suggested the anti-inflammatory properties of the B. juncea spice/herb (Figure 6).

From a near perspective, data from this research showed that thioacetamide could interact with DNA and induce changes in the hepatic cells (Figure 4). While TAA/challenged group damage DNA was demonstrated by an increase in the tail moment. However, B. juncea therapy. Ethanolic extract in normal or nanoform decreased DNA damage dramatically and reversed the comet's length back to normal. These findings can be interpreted on the basis of the antioxidant phytochemical components contained in the mustard extract, which carry a high flavonoid diffusion rate into the membranes, allowing them to scavenge oxy radicals in the lipid bilayer at several sites. The results may be in harmony with the results of Zargar et al. [49], as he used rutin before two weeks of TAA assault and resulted in the complete reversal of TAA-mediated hepatic toxicity. Our results also go in the same connection with Ansar et al. [50], who proposed that flavonoids may also be involved in the indirect induction of detoxifying genes, which may promote detoxification of TAA and decrease its toxicity.

It is noteworthy that this study was designed to investigate the mustard extract in its natural or in its nano sort either as a prophylactic or as a treatment against the insult of TAA inducing acute liver failure. We would like to draw to the reader's attention that treatment with mustard nano form has shown superiority over the ethanol normal extract formula. The matter which reflects the efficiency of the nanoparticles in term of their existence of the essential functional groups to make AgNPs very stable and prevent it from being anchored. In addition, the existence of the bioactive molecules on the surface of AgNPs may increase its efficacy and bioavailability. It can also enhance its solubility, improve plasma half-life, preventing degradation in the intestinal environment and increasing permeation in the small intestine, which may confer strong antioxidative activity [51,52]. Although the results of the present study support mustard as a great candidate for liver, It appears that mustard and its nanoparticles may initiate comets, Table 5. Mustard in both forms cannot efficiently switch/ reverse the DNA fragmentations back or close to the normal. This result may be credited to a 
few leftover pesticides within the mustard seed itself or may predict some toxic components contained within the mustard. Azubuike et al. [12]. Duy and Trang [53] recorded that B. juncea seeds contain saponins, flavonoids and tannins. In expansion, mustard oil is well known to contain glycerides of erucic acid, which is considered harmful to human wellbeing. Hence, these observations recommend that drawn-out utilization of $B$. juncea seed extract may have some hepatotoxic impacts. The matter which motivates more extensive research in order to explore the behind plausible mechanism.

\section{Conclusions}

Our experimental findings demonstrated that the plant under investigation (mustard) possesses a potent antioxidative-inflammatory effect, and its nanostructure is more potent than its typical. The LC/MS Phytochemical analysis of the plant extract demonstrates the presence of a plethora of powerful compounds like phenolic and flavonoids compounds, which brought possible mechanism of hepatoprotective activity due to their free radical scavenging and antioxidant properties in addition to their anti-inflammatory effects. These properties are mediated by downregulating the liver function enzymes, lipid profile, oxidative stress, expression of TNF- $\alpha$, and IL-6. in both serum and tissue. Although we acknowledge these results as not only has it been revealed that the ethanolic concentration of Brassica juncea L. has a reasonable measure of safety and risks, the study also provided new insights into the possible role of mustard in the treatment of acute liver injury.

Author Contributions: S.A.H. designed the experimental work S.A.H. \& W.M.A. performed the experiment and the formal statistical analysis. A.M.E.H. was responsible for extraction and phytochemical analysis of the plant by LC/MS. A.M.S. and E.E. were responsible for data collection and curation. S.A.H. was responsible for drafting and editing the manuscript. O.H. was responsible for pathological \& immunohistopathological analysis and made a substantial contribution in editing and revising the manuscript. All authors have read and agreed to the published version of the manuscript.

Funding: This study was thankfully supported by the "Researchers Supporting Project", King Saud University, Riyadh, Saudi Arabia. through the grant number RSP/2020/45.

Acknowledgments: The authors would like to thank the Researchers Supporting Project, King Saud University, Riyadh, Saudi Arabia for the funding of this study [grant number RSP/2020/45]. We would also like to extend our gratitude to those individuals who have made a valuable contribution to this work.

Conflicts of Interest: The authors declare no potential conflict of interest.

\section{References}

1. Real, M.; Barnhill, M.S.; Higley, C.; Rosenberg, J.; Lewis, J.H. Drug-induced liver injury: Highlights of the recent literature. Drug Saf. 2019, 42, 365-387. [CrossRef] [PubMed]

2. Dwivedi, D.K.; Jena, G.B. Glibenclamide protects against thioacetamide-induced hepatic damage i Wistar rat: Investigation on NLRP3, MMP-2, and stellate cell activation. Naunyn Schmiedeberg Arch. Pharmacol. 2018, 391, 1257-1274. [CrossRef] [PubMed]

3. Koblihová, E.; Mrazova, I.; Vernerova, Z.; Ryska, M. Acute liver failure induced by thioacetamide: Selection of optimal dosage in Wistar and Lewis rats. Physiol. Res. 2014, 63, 491-503. [CrossRef]

4. De Minicis, S.; Candelaresi, C.; Agostinelli, L.; Taffetani, S.; Saccomanno, S.; Rychlicki, C.; Trozzi, L.; Marzioni, M.; Benedetti, A.; Svegliati-Baroni, G. Endoplasmic Reticulum stress induces hepatic stellate cell apoptosis and contributes to fibrosis resolution. Liver Int. 2012, 32, 1574-1584. [CrossRef] [PubMed]

5. Crosas-Molist, E.; Fabregat, I. Role of NADPH oxidases in the redox biology of liver fibrosis. Redox Biol. 2015, 6, 106-116. [CrossRef] [PubMed]

6. Mittal, M.; Siddiqui, M.R.; Tran, K.; Reddy, S.P.; Malik, A.B. Reactive oxygen species in inflammation and tissue injury. Antioxid. Redox Signal. 2014, 20, 1126-1167. [CrossRef] [PubMed]

7. Hussain, M.A.; Khan, M.Q.; Hussain, N.; Habib, T. Antibacterial and antifungal potential of leaves and twigs of Viscum album L. J. Med. Plants Res. 2011, 5, 5545-5549. 
8. Parikh, H.; Pandita, N.; Khanna, A. Phytoextract of Indian mustard seeds acts by suppressing the generation of ROS against acetaminophen-induced hepatotoxicity in HepG2 cells. Pharm. Biol. 2015, 53, 975-984. [CrossRef]

9. Manohar, P.R.; Pushpan, R.; Rohini, S. MustardanditsusesinAyurveda. Indian J. Tradit. Know. 2009, 8, 400-404.

10. Kumar, V.; Thakur, A.K.; Barothia, N.D.; Chatterjee, S.S. Therapeutic potentials of Brassica juncea: An overview. Tang 2011, 1, e2. [CrossRef]

11. Walia, A.; Malan, R.; Saini, S.; Saini, V.; Gupta, S. Hepatoprotective effects from the leaf extracts of Brassica juncea in CCl4 induced rat model. Pharm. Sin. 2011, 2, 274-285.

12. Azubuike, N.C.; Okwuosa, C.N.; Maduakor, U.C.; Onwukwe, O.S.; Onyemelukwe, A.O.; Ogu, C.O.; Akande, A. Effects of methanolic extract of Brassica juncea seeds on biochemical parameters and histological integrity of the heart and liver of albino rats. Int. J. Morphol. 2019, 37, 237-240. [CrossRef]

13. El-Hagrassy, A.M.; Osman, A.F.; Mhafouz Eskander, D.; Nassar, M.I. Chemical Constituents and Cytotoxic Evaluation of Abelmoschusesculentus L. Leaves Grown in Egypt. J. Chem. Pharm. 2019, 11, 1-13.

14. El-Hagrassy, A.M.; Elkhateeb, A.; Sameh, H.R.; El-Sayed, S.A.-H.; Marzouk, M.M. LC-ESI-MS profile, anti-oxidant activity and cytotoxic screening of Oligomerislinifolia (Vahl) Macbr. (Resedaceae). J. Appl. Pharm. Sci. 2017, 7, 43-47.

15. Marzouk, M.M.; Sameh, H.R.; Elkhateeb, A.; El-Shabrawy, M.; El-Sayed, S.A.-H.; Kawashty, S.A. Comparative study of Mentha species growing wild in Egypt: LC-ESI-MS analysis and chemosystematic significance. J. Appl. Pharm. Sci. 2018, 8, 116-122.

16. Hassan, S.A.; Hammam, O.; Hussein, S.O.; Aziz, W.M. The Conquering influence of the Nano extracts of pomegranate peels and pistachio leaves in amelioration of acute liver failure. bioRxiv 2020. [CrossRef]

17. Elavazhagan, T.; Arunachalam, K.D. Memecylonedule leaf extract mediated green synthesis of silver and gold nanoparticles. Int. J. Nanomed. 2011, 6, 1265. [CrossRef]

18. Buege, J.A.; Aust, S.D. Microsomal lipid peroxidation. Method Enzym. 1978, 52, 302-310.

19. Moron, M.S.; Depierre, J.W.; Mannervik, B. Levels of glutathione, glutathione reductase and glutathione S-transferase activities in rat lung and liver. Biochim. Biophys. Acta 1979, 582, 67-78. [CrossRef]

20. Nishikimi, M.; Rao, N.A.; Yagi, K. The occurrence of superoxide anion in the reaction of reduced phenazinemethosulfate and molecular oxygen. Biochem. Biophys. Res. Commun. 1972, 46, 849-854. [CrossRef]

21. Moshage, H.; Kok, B.; Huizenga, J.R.; Jansen, P.L. Nitrite and nitrate determinations in plasma: A critical evaluation. Clin. Chem. 1995, 41, 892-896. [CrossRef] [PubMed]

22. Bradford, M.M. A rapid and sensitive method for the quantitation of microgram quantities of protein utilizing the principle of protein-dye binding. Anal. Biochem. 1976, 72, 248-254. [CrossRef]

23. Masoomi, K.M.; Jafari, S.M.; Zaree, M.A.; Jafari, S.A.; Khatibi, S.R. Effect of acute toxicity of cadmium in mice kidney cells. Iran. J. Toxicol. 2012, 6, 691-698.

24. Slaoui, M.; Fiette, L. Histopathology procedures: From tissue sampling to histopathological evaluation. In Drug Safety Evaluation; Humana Press: Totowa, NJ, USA, 2011; pp. 69-82.

25. Pareek, V.; Bhargava, A.; Gupta, R.; Jain, N.; Panwar, J. Synthesis and applications of noble metal nanoparticles: A review. Adv. Sci. Eng. Med. 2017, 9, 527-544. [CrossRef]

26. Mali, R.G. Cleomeviscosa (wild mustard): A review on ethnobotany, phytochemistry, and pharmacology. Pharm. Biol. 2010, 48, 105-112. [CrossRef]

27. Melrose, J. The Glucosinolates: A SulphurGlucoside Family of Mustard Anti-Tumour and Antimicrobial Phytochemicals of Potential Therapeutic Application. Biomedicines 2019, 7, 62. [CrossRef]

28. Nawaz, H.; Shad, M.A.; Muzaffar, S. Phytochemical Composition and Antioxidant Potential of Brassica. In Brassica Germplasm: Breeding and Utilization; Intech Open: London, UK, 2018.

29. Chang, S.T.; Wu, J.H.; Wang, S.Y.; Kang, P.L.; Yang, N.S.; Shyur, L.F. Antioxidant activity of extracts from Acacia confusa bark and heart wood. J. Agric. Food Chem. 2001, 49, 3420-3424. [CrossRef]

30. Simon-Giavarotti, K.A.; Giavarotti, L.; Gomes, L.F.; Lima, A.F.; Veridiano, A.M.; Garcia, E.; Mora, A.O.A.; Fernández, V.; Videla, L.A.; Junqueira, V.B. Enhancement of lindane-induced liver oxidative stress and hepatotoxicity by thyroid hormone is reduced by gadolinium chloride. Free Radic. Res. 2002, 36, 1033-1039. [CrossRef]

31. Yang, H.Y.; Kim, K.S.; Lee, Y.H.; Park, J.H.; Kim, J.H.; Lee, S.Y.; Kim, Y.M.; Kim, I.S.; Kacew, S.; Lee, B.M.; et al. Dendropanaxmorbifera ameliorates thioacetamide-induced hepatic fibrosis via TGF- $\beta 1 /$ Smads pathways. Int. J. Biol. Sci. 2019, 15, 800. [CrossRef] 
32. Khaled, H. Possible hepatoprotective Effects of Mustard Seed Extract against Paracetamol-Induced Liver Injury in Male Albino Rat. Catrina Int. J. Environ. Sci. 2018, 17, 85-90.

33. Le, B.; Anh, P.T.; Yang, S.H. Enhancement of the Anti-Inflammatory Effect of Mustard Kimchi on RAW 264.7 Macrophages by the Lactobacillus plantarum Fermentation-Mediated Generation of Phenolic Compound Derivatives. Foods 2020, 9, 181. [CrossRef] [PubMed]

34. Carocho, M.; Ferreira, I.C. A review on antioxidants, prooxidants and related controversy: Natural and synthetic compounds, screening and analysis methodologies and future perspectives. Food Chem. Toxicol. 2013, 51, 15-25. [CrossRef] [PubMed]

35. Mazumder, A.; Dwivedi, A.; Du Plessis, J. Sinigrin and its therapeutic benefits. Molecules 2016, $21,416$. [CrossRef] [PubMed]

36. Lee, J.J.; Kim, H.A.; Lee, J. The effects of Brassica Juncea, L. leaf extract on obesity and lipid profiles of rats fed a high-fat/high-cholesterol diet. Nutr. Res. Pract. 2018, 12, 298-306. [CrossRef]

37. Stocker, R.; Yamamoto, Y.; McDonagh, A.F.; Glazer, A.N.; Ames, B.N. Bilirubin is an antioxidant of possible physiological importance. Science 1987, 235, 1043-1046. [CrossRef]

38. Jangi, S.; Otterbein, L.; Robson, S. The molecular basis for the immunomodulatory activities of unconjugated bilirubin. Int. J. Biochem. Cell Biol. 2013, 45, 2843-2851. [CrossRef]

39. Horsfall, L.J.; Nazareth, I.; Pereira, S.P.; Petersen, I. Gilbert's syndrome and the risk of death: A population-based cohort study. J. Gastroenterol. Hepatol. 2013, 28, 1643-1647. [CrossRef]

40. Mao, F.; Zhu, X.; Lu, B.; Li, Y. The association between serum bilirubin level and electrochemical skin conductance in Chinese patients with type 2 diabetes. Int. J. Endocrinol. 2018, 2018. [CrossRef]

41. Rawat, V.; Bortolussi, G.; Gazzin, S.; Tiribelli, C.; Muro, A.F. Bilirubin-induced oxidative stress leads to DNA damage in the cerebellum of hyperbilirubinemic neonatal mice and activates DNA double-strand break repair pathways in human cells. Oxid. Med. Cell. Longev. 2018, 2018. [CrossRef]

42. Mahmoud, M.F.; Zakaria, S.; Fahmy, A. Can chronic nitric oxide inhibition improve liver and renal dysfunction in bile duct ligated rats? Adv. Pharmacol. Pharm. Sci. 2015, 2015. [CrossRef]

43. Iwakiri, Y.; Kim, M.Y. Nitric oxide in liver diseases. Trends Pharmacol. Sci. 2015, 36, $524-536$. [CrossRef] [PubMed]

44. Keshari, A.K.; Srivastava, R.; Singh, P.; Yadav, V.B.; Nath, G. Antioxidant and antibacterial activity of silver nanoparticles synthesized by Cestrum nocturnum. J. Ayurveda Integr. Med. 2020, 11, 37-44. [CrossRef] [PubMed]

45. López-García, M.P.; Sanz-González, S.M. Peroxynitrite generated from constitutive nitric oxide synthase mediates the early biochemical injury in short-term cultured hepatocytes. FEBS Lett. 2000, 466, 187-191. [CrossRef]

46. Mannaa, F.A.G.; Abdel-Wahhab, K. Physiological potential of cytokines and liver damages. Hepatoma Res. 2016, 2, 131-143. [CrossRef]

47. Del Campo, J.A.; Gallego, P.; Grande, L. Role of inflammatory response in liver diseases: Therapeutic strategies. World J. Hepatol. 2018, 10, 1. [CrossRef]

48. Wang, X.; Shen, C.; Yang, J.; Yang, X.; Qin, S.; Zeng, H.; Wu, X.; Tang, S.; Zeng, W. Alpha-Fetoprotein as a Predictive Marker for Patients with Hepatitis B-Related Acute-on-Chronic Liver Failure. J. Gastroenterol. Hepatol. 2018, 2018. [CrossRef]

49. Zargar, S.; Wani, T.A.; Alamro, A.A.; Ganaie, M.A. Amelioration of thioacetamide-induced liver toxicity in Wistar rats by rutin. Int. J. Immunopathol. Pharmacol. 2017, 30, 207-214. [CrossRef]

50. Ansar, S.; Siddiqi, N.J.; Zargar, S.; Ganaie, M.A.; Abudawood, M. Hepatoprotective effect of Quercetin supplementation against Acrylamide-induced DNA damage in wistarrats. BMC Complement. Altern. Med. 2016, 16, 327. [CrossRef]

51. Surendran, S.P.; Thomas, R.G.; Moon, M.J.; Jeong, Y.Y. Nanoparticles for the treatment of liver fibrosis. Int. J. Nanomed. 2017, 12, 6997. [CrossRef] 
52. Zhang, H.; Jacob, J.A.; Jiang, Z.; Xu, S.; Sun, K.; Zhong, Z.; Varadharaju, N.; Shanmugam, A. Hepatoprotective effect of silver nanoparticles synthesized using aqueous leaf extract of Rhizophoraapiculata. Int. J. Nanomed. 2019, 14, 3517. [CrossRef]

53. Duy, N.L.B.; Trang, D.T.D. Preliminary phytochemical, acute oral toxicity and anticonvulsant activity of the seed extract of Brassica juncea. Eur. J. Med. Plants 2016, 14, 1-9. [CrossRef]

Publisher's Note: MDPI stays neutral with regard to jurisdictional claims in published maps and institutional affiliations.

(C) 2020 by the authors. Licensee MDPI, Basel, Switzerland. This article is an open access article distributed under the terms and conditions of the Creative Commons Attribution (CC BY) license (http://creativecommons.org/licenses/by/4.0/). 